\title{
Sigilo na Atenção em DST/AIDS: do Consultório aos Processos
}

\section{Organizacionais}

Confidentiality in the STD/AIDS Care: from the Doctor's Office to the Organizational Process Confidencialidad en el Cuidado de ETS/SIDA: del Consultorio a los Procesos

Organizacionales

\section{Renata Bellenzani}

Universidade Federal de Mato Grosso do Sul, Campo Grande, MS, Brasil.

\section{Rúbia de Fátima Mendes}

Universidade Federal de Mato Grosso do Sul, Campo Grande, MS, Brasil.

\section{Resumo}

O sigilo integra o cuidado em saúde para proteger as pessoas com HIV/Aids, ou "sob suspeita", do estigma/discriminação. A partir de observações etnográficas buscou-se compreender sentidos e práticas envolvendo sigilo e privacidade em um serviço especializado em DST/Aids, num município pequeno, no Estado de Mato Grosso do Sul. A análise, de cunho construcionista social, de episódios e conversações evidenciou a valorização do sigilo no plano discursivo, mas em razão de limites tênues entre privacidade e sociabilidade em municípios interioranos "quebras de sigilo" eram práticas sociais naturalizadas, não intencionais, tampouco reconhecidas como falhas técnicas/éticas. A análise revelou que fluxos e processos de trabalho violavam a privacidade de usuários. O sentido de manter sigilo era, predominantemente, o de não revelar a soropositividade dos pacientes; não se associava aos modos de organização do trabalho. Acreditamos que ao problematizarem os sentidos e implicações locais de suas práticas, as equipes podem construir novas práticas e realidades institucionais adensadas pelos referenciais do Cuidado, Humanização e Atenção Psicossocial. Palavras-chaves: HIV/AIDS, Sigilo, Privacidade, Cuidado em Saúde, Humanização.

\footnotetext{
Abstract

Confidentiality is part of health care in order to protect people with HIV / AIDS or "under suspicion" from stigma and discrimination. The objective of this paper is, using ethnographic observations, to understand meanings and practices involving confidentiality and privacy in a public health care service specialized in STD/AIDS, in a small town in Mato Grosso do Sul,
} 
Brazil. Social constructionist analysis of interactions and conversations revealed the appreciation of confidentiality at the discourse level, but because of tenuous boundaries between privacy and sociability in small towns, "breaches of confidentiality" were naturalized as social practices, unintentional, and not recognized as technical failures/ethics. Fluxes and work processes violated the privacy of users. The meaning of maintain confidentiality was, predominantly not reveal the HIV status of patients and was not associated with the process and practices of work. By the elucidation of the meanings and implications of their work performances, teams can build new practices and institutional realities based on Care, Humanization and Psychosocial Care.

Keywords: HIV/AIDS, Confidentiality, Privacy, Health Care, Humanization of Assistance.

\section{Resumen}

Sigilo es parte de la atención de la salud para proteger a las personas con VIH / SIDA, o "bajo sospecha", del estigma / discriminación. A partir de observaciones etnográficas, se objetiva la comprensión de significados y prácticas relacionados con el sigilo y la privacidad, en un servicio especializado de ETS/SIDA, en una pequeña ciudad en Mato Grosso do Sul, Brasil. El análisis construccionista social de los episodios y las conversaciones, reveló la apreciación del sigilo en plan discursivo, pero más debido a los límites tenues entre la intimidad y la sociabilidad en los pequeños pueblos del interior del país, "romper con el secreto" era una práctica social natural, no intencional y tampoco reconocida como falla técnica/étnica. Los flujos y procesos del trabajo violaban la privacidad de los usuarios. El sentido de mantener la confidencialidad es, sobre todo, no revelar el estado serológico de los pacientes, no estaban asociados a los modos de organización del trabajo. Al dilucidarse los sentidos y implicaciones locales sus actuaciones, los equipos pueden crear nuevas prácticas y realidades institucionales, orientadas por referenciales del Cuidado, Humanización y Atención Psicosocial.

Palabras clave: VIH/SIDA, Confidencialidad, Privacidad, Atención de la Salud, Humanización de la Asistencia. 


\section{Introdução}

\section{A relevância do problema}

A política brasileira de AIDS, fruto das interlocuções entre o movimento social organizado e as instâncias da saúde pública desde o final da década de 80 e início de 90, desenvolveu-se levando em consideração o estigma em relação à aids e as discriminações vivenciadas pelas pessoas com suspeita ou diagnóstico de HIV. Foi uma preocupação à época as possíveis implicações àqueles que estivessem em vias de realizar o exame de detecção ou ao buscarem atendimento por sintomas da doença - sem cura, e a princípio associada no imaginário aos hábitos e condutas consideradas anormais ou moralmente condenáveis tais como: usar drogas injetáveis, ser gay, prostituta, ter vida sexual "promíscua”. Essas práticas ou identidades marcadas por diversos preconceitos se integraram, historicamente, na construção do famoso jargão "grupos de risco" (Castanheira, 2002). A autora relembra que efetivar o acesso à assistência das pessoas suspeitas de estarem com aids ou diagnosticadas ia além do esforço de garantir o direito aos cuidados médicos especializados no SUS, incluindo também a necessidade de proteger as pessoas da discriminação, o que se desdobrou em uma configuração do Programa de Aids, em sua criação, diferente de outros programas de saúde. Sua relativa "verticalização" culminou na criação de serviços especializados e próprios desse programa ao invés de sua incorporação em serviços ou programas já existentes.

Especificamente com relação à prevenção em saúde sexual e à atenção clínica às pessoas com sintomas de doenças sexualmente transmissíveis (DST) como sífilis, hepatite B, gonorréia, HPV, HIV/Aids, entre outras, uma rede de serviços é preconizada pelo Programa Nacional de DST/Aids (Brasil, 1999), entre eles os Centros de Testagem e Aconselhamento (CTA) e os Serviços de Assistência Especializada (SAE-DST/Aids).

Os temas como sigilo, privacidade, confidencialidade, reconhecimento e enfrentamento do estigma da Aids, necessidade de ações de proteção contra a discriminação e a promoção dos direitos humanos têm sido valorizados nos debates sobre a humanização da assistência, a qualidade do cuidado (Ayres, 2004a; 2004b) e sobre a atenção psicossocial na prevenção e assistência em HIV/Aids nos serviços de saúde (Paiva et. al., 2002; Paiva, 2007). Isso porque nos serviços que lidam com a saúde sexual são objetos de diálogos e de intervenções as experiências da afetividade, da sexualidade, das práticas sexuais hetero e 
homoafetivas, das identidades sexuais e de gênero, na elaboração, por exemplo, do raciocínio sobre as vulnerabilidades e riscos envolvendo as circunstâncias e as formas de transmissão do HIV e das DST (s) em geral. Todos esses temas são significados socialmente como "da vida íntima e privada", aludindo à relevância do sigilo e da confidencialidade. As discriminações a que estão suscetíveis as pessoas que vivem relações homoafetivas, por exemplo, podem se somar às discriminações por ser portador do HIV/Aids, por desejar realizar o teste anti-HIV, ou simplesmente por solicitar preservativo, ao "se encaixar" em algum tipo de estereótipo desvalorizado socialmente numa normatividade mais tradicional, por exemplo: uma mulher casada interessada em adquirir preservativo, questionada implicitamente se utiliza preservativo com o esposo ou se está "pulando a cerca", nos termos da conversação cotidiana.

Segundo Parker e Aggleton (2001), processos de discriminação têm em sua base a estigmatização que implica a desvalorização social de determinados atributos, como no caso das pessoas diagnosticadas com o vírus HIV, que passam a ser desacreditadas, desqualificadas, o que compromete sua sociabilidade e o exercício de seus direitos. Os autores alertam sobre a maneira individualista que o conceito de estigmatização tem sido historicamente utilizado no campo da aids, ou seja, como algo estático, à parte do processo social em que é produzida.

Inspirados em Goffman (1963), Parker e Aggleton (2001) resgatam a perspectiva histórica do estigma, termo criado pelos gregos, cujo significado desde seu surgimento remete aos estigmas malignos da loucura e da doença. Remetendo à noção de uma marca ou impressão, na Grécia se referia aos sinais corporais produzidos no corpo com fogo ou materiais cortantes que simbolizavam um mau sobre o status moral das pessoas que os apresentavam: um escravo, um criminoso ou um traidor, alguém a ser evitado.

Nesse sentido, Parker e Aggleton (2001) afirmam que independentemente do estigma e da discriminação em função do HIV/Aids, ou além desses, existem determinados domínios da vida pessoal e social que estão quase que, universalmente, presentes em todos os países e culturas como expressivos da constituição dos processos socioculturais de estigma e de discriminação. Trata-se dos estigmas em relação à sexualidade, ao gênero, à raça/etnia e em relação à pobreza/marginalização. Conforme “encarnem" algum desses estigmas, determinadas pessoas e grupos tenderão a sofrer discriminações. Essa discussão ancora-se na literatura mais abrangente 
sobre as relações entre sexualidade, cultura, política e sociedade, que destaca a atual instabilidade/fluidez das identidades sexuais e à imbricação da sexualidade em relações de poder e hierarquias sociais (Carrara \& Simões, 2007).

De acordo com diferentes atributos pessoais, práticas e orientações sexuais, contextos e dinâmicas sociais, pessoas são respeitadas ou não, valorizadas ou estigmatizadas, protegidas ou agredidas, escutadas ou silenciadas, expressando a desigualdade no gozo dos direitos, a proteção dos direitos de uns e a violação dos direitos de outros. Nesse cenário, compreende-se a enorme preocupação das pessoas que vivem com HIV/Aids com a não divulgação da própria condição sorológica. Uma das dimensões que se mostrou mais relacionada com prejuízos à qualidade de vida em estudo com mulheres portadoras de HIV/AIDS foi a "preocupação com o sigilo sobre a infecção" (Galvão, Cerqueira \& Marcondes-Machado, 2004, p. 432). Segundo os autores, ao terem a soropositividade revelada essas mulheres vivenciam discriminação, segregação, falta de recursos sociais, dificuldades financeiras, rompimentos de relações afetivas, dificuldades na sexualidade, entre outros de modo que viver e enfrentar a doença guarda significativo desgaste, comprometendo sua qualidade de vida.
As violações de direitos resultantes dos processos de estigmatização e de discriminação associados à aids, têm sido descritas por diversos autores como parte integrante da experiência cotidiana das pessoas vivendo com HIV/Aids, e também, implicadas na negligências ou discriminações que experimentam nos serviços de saúde (Paiva, Lima, Santos, Ventura-Filipe \& Segurado, 2002).

\section{Sigilo, privacidade e confidencialidade: questões centrais para humanização dos serviços de DST/Aids}

O sigilo profissional com relação aos assuntos tratados entre profissionais de saúde e paciente, assim como o respeito à sua privacidade, ganharam destaque com as proposições mais recentes da Política Nacional de Humanização (PNH) que tem por objetivo qualificar práticas de gestão e de atenção em saúde. $O$ foco está na

problemática adjetivada como desumanização, conceito síntese que revela a percepção da população e de trabalhadores da saúde frente a problemas como as filas, a insensibilidade dos trabalhadores frente ao sofrimento das pessoas, os tratamentos desrespeitosos, o isolamento das pessoas de suas redes sócio-familiares nos procedimentos, consultas e internações, as práticas de gestão autoritária, as deficiências nas 
condições concretas de trabalho, incluindo a degradação nos ambientes e das relações de trabalho, etc, [que] derivam de condições precárias da organização de processos de trabalho, na perspectiva da PNH (Brasil, 2010, p.6).

Um dos principais dispositivos proposto pela PNH é o acolhimento compreendido como:

um modo de operar os processos de trabalho em saúde de forma a atender a todos que procuram os serviços de saúde, ouvindo suas solicitações e assumindo no serviço uma postura capaz de acolher, escutar e pactuar respostas mais adequadas aos usuários. Implica prestar um atendimento com resolutividade e responsabilização (Brasil, 2006, p.21).

Nos acolhimentos e na assistência à saúde desenvolvida nos Serviços de Assistência Especializada em DST/Aids (SAE), a partir de ações de prevenção e tratamento dos agravos de saúde sexual, os temas sigilo, privacidade e confidencialidade ganham especial relevância, conforme discutiremos nesse trabalho.

A noção de sigilo profissional é definida como "dever ético que impede à revelação de assuntos confidenciais ligados a profissão" (Sales-Peres, Sales-Peres, Fantini, Freitas, Oliveira, Silva \& Chaguri, 2008, p.7). Segundo Garcia (1998) o sigilo profissional remete às necessidades e ao direito do cidadão, ao respeito pela sua intimidade o que, por sua vez, passou a ser associado à noção de confidencialidade nas interações entre profissionais e sujeitos.

O sigilo profissional é especialmente valorizado na assistência em saúde sexual, compreendida de modo geral como a esfera da atenção à saúde que tem como foco a promoção do exercício da sexualidade, com acesso às informações, em condições para vivenciar o prazer e proteger-se das doenças sexualmente transmissíveis, livre de coerções e discriminações (Hera, 1999; Brasil, 2006a).

A assistência à saúde sexual deve estar orientada pelo respeito e promoção dos direitos sexuais, compreendidos como direitos humanos (Côrrea \& Ávilla, 2003). No que concerne às questões de saúde sexual e reprodutiva, constitui um direito sexual o "direito a serviços de saúde que garantam privacidade, sigilo e atendimento de qualidade e sem discriminação", (Brasil, 2006a, p. 4).

$\mathrm{O}$ acolhimento e a assistência em saúde sexual, especificamente com pessoas em situação de testagem para detecção do HIV, de consulta, aconselhamento, exames e tratamentos em função de sintomas ou queixas de DST, condicionam-se à disponibilidade dos usuários em expor sua privacidade ao profissional no que se refere às suas práticas e parcerias sexuais. 
Dependem, em alguns casos, que as pessoas compartilhem práticas sociais relacionadas a outras esferas morais como, por exemplo: o uso de drogas injetáveis, em função do compartilhamento de seringas; ou o abuso de álcool e outras drogas que podem ampliar a vulnerabilidade ao sexo sem preservativo. Para tanto, é imprescindível que se constitua um acordo de confidencialidade.

Privacidade e confidencialidade são princípios complexos e relacionados como afirmam Massarollo, Sacardo e Zoboli (2006). A privacidade é definida por Abdalla e Nichiata (2008, p. 145) como um conjunto de informações que uma pessoa constitui sobre si mesma e "que pode decidir mantê-las sob seu exclusivo controle, ou comunicar, decidindo em que medida e a quem, quando, onde e em que condições o outro poderá acessar as informações". A confidencialidade, por sua vez, deve garantir que as informações confidenciadas não serão disseminadas a outras pessoas sem prévia autorização do usuário. "A privacidade das informações é um direito dos usuários do serviço, ao mesmo tempo em que a confidencialidade é um dever dos profissionais em relação às informações geradas e confiadas no relacionamento profissional-usuário (Abdalla \& Nichiata, 2008, p. 145).

Por ser o trabalho em saúde "relacional/intersubjetivo e de intervenção de um sujeito sobre outro" (Sá, 2009, p. 656), devendo ocorrer a partir do cuidado solidário, paradoxalmente, podem ocorrer negligências, omissões, desrespeitos, violações de direitos, como a discriminação em função de determinados atributos. $\mathrm{Ou}$ ainda, a exposição indevida e não consentida de assuntos de ordem privada, na medida em que a confidencialidade e o sigilo profissional não sejam preservados.

Enquanto um imperativo ético profissional a preservação do sigilo deve mobilizar os profissionais de saúde a desenvolverem posturas, modos de agir e adequações no processo de trabalho em saúde a fim de proteger usuários de incidentes desse tipo.

A manutenção do sigilo deve ocorrer não somente quanto à condição sorológica de pacientes, por parte dos profissionais envolvidos com a assistência clínica, mas também com relação a resultados de exames, e quanto a quaisquer diálogos e procedimentos de tratamento ou preventivos. O sigilo é uma das dimensões para promover uma assistência humanizada às pessoas com HIV (Oliveira, Landroni, Silva \& Ayres (2005), constituindo-se num modo de protegê-las frente ao risco de discriminações, não somente pelo estigma em relação à aids, mas também pelos estigmas em relação a outros atributos, condições, doenças, comportamentos e identidades. 
Objetivo do trabalho, método e características do serviço pesquisado

O objetivo do presente trabalho é compreender os sentidos e as práticas em torno do sigilo, da confidencialidade e da privacidade que se produzem no cotidiano do trabalho de uma equipe, no acolhimento e na atenção desenvolvidas em um Serviço de Assistência Especializada em DST/Aids (SAE) de um município de pequeno porte, no Estado de Mato Grosso do Sul.

O serviço em questão, à época do estudo ${ }^{1}$, contava com uma equipe composta por médico generalista (01); farmacêutico (01); enfermeiro (01); auxiliar de enfermagem (01); técnico em enfermagem (01), biomédico (01), auxiliar de limpeza (01) e coordenador (01). ${ }^{2}$ Segundo a coordenação, estavam cadastradas entre 150 a 200 pessoas com HIV/Aids, de cinco diferentes municípios da região dos quais o serviço era referência. Além de atuar como serviço especializado em DST/Aids, também servia ao atendimento de necessidades clínicas de outra natureza, ações de vigilância e prevenção de outros agravos, caracterizando-se como um serviço misto, de acordo com a coordenação.

Foram realizadas observações etnográficas em diferentes dias da semana, manhãs e tardes, pelo período de dois meses, (maio e junho de 2009), com a ciência dos profissionais do serviço sobre os objetivos do estudo. Seis auxiliares de pesquisa estiveram presentes no SAE, distribuídos em duplas, totalizando aproximadamente 72 horas de observação. Todos os auxiliares eram estudantes do terceiro ano de graduação em psicologia e foram supervisionados durante todo $\mathrm{o}$ trabalho de campo, em reuniões semanais.

Durante as observações utilizou-se um roteiro adaptado de Castanheira (2002), que elencava os espaços do serviço e respectivos aspectos a serem observados, entre eles: a área externa, no caso a garagem da casa térrea onde funcionava o serviço, as dependências da sala de espera (com cadeiras para usuários e uma mesa, identificada como a recepção); a sala de cuidados de enfermagem; a sala de coleta de exames, a farmácia onde eram retirados medicamentos e os corredores que conectavam os espaços.

É importante destacar que por se tratar de um serviço de pequeno porte, as jornadas de trabalho dos profissionais não eram integrais e o atendimento médico restringia-se a um ou dois dias da semana. Durante a maior parte do tempo a equipe completa não estava presente e o fluxo de usuários era baixo, aumentando em dias específicos de acordo com a rotina planejada, por exemplo, na semana do mês em que eram distribuídas a cada paciente suas medicações antirretrovirais e, principalmente, nos dias de atendimento 
médico. Essa característica repercutiu no processo das observações etnográficas, que adquiriram uma conotação mais interativa e participativa dos pesquisadores em relação ao funcionamento do serviço. Havendo poucas pessoas presentes, produziam-se circunstâncias de maior proximidade entre os auxiliares de pesquisa, os usuários que entrassem no serviço (dado que, geralmente, não eram muitos ao mesmo tempo) e os trabalhadores que estivessem ali. Alguns dos trabalhadores e dos pesquisadores já se conheciam "de vista" e boa parte das pessoas que entravam no serviço para algum tipo de atendimento eram conhecidos pela equipe do SAE.

O número pequeno de pessoas interagindo favorecia as conversações e, também, o envolvimento dos auxiliares de pesquisa em algumas ações, numa postura solidária ao serviço, pois, na visão da equipe o serviço tinha "falta de pessoal", de modo que "todos deviam fazer um pouco de tudo", mesmo com a tranqüilidade geralmente observada na dinâmica institucional. As observações e a coleta de depoimentos ocorreram, então, em meio a algumas participações, ora solicitadas, ora por iniciativa dos pesquisadores, na rotina do serviço, entre elas, destacamos: atuar em alguns momentos na recepção, recebendo algum usuário enquanto $\mathrm{o}$ trabalhador designado para essa função estivesse ocupado com outra tarefa; ajudar na arrumação de prontuários; na mudança de disposição das mobílias; na organização de documentos; separação de insumos, etc. Em alguns momentos $\mathrm{s}$ observadores compartilharam o cafezinho com os trabalhadores. Durante as conversações, às vezes por serem identificados como "os de fora" ou "da psicologia" lhes eram feitos alguns "desabafos", reclamações, ou mesmo críticas sobre um colega de equipe ou sobre a chefia. Cientes de que os observadores pesquisavam os temas: acesso, humanização e acolhimento, alguns conversavam como se dissessem "vou te contar, então, dessas coisas que vocês estão estudando".

As observações e os assuntos das conversações eram registrados nos diários de campo por cada observador, que ao sair do serviço produzia o mais breve possível um relatório digitado, mais completo e descritivo. Os registros se constituíam por episódios e fatos presenciados, assim como suas circunstâncias; por descrições, opiniões ou relatos de episódios já ocorridos, compartilhados pelos atores, especificamente, com os auxiliares de pesquisa (depoimentos informais); por falas espontâneas de trabalhadores ou de usuários, não necessariamente dirigidas aos auxiliares de pesquisa, que se desenrolavam nas conversas em geral. Os relatórios produzidos por cada observador eram objeto de leituras e discussões coletivas nas supervisões semanais quando, a partir de 
questionamentos do grupo, eram adensados com informações, a fim de um maior detalhamento sobre as circunstâncias, os atores e os sentidos envolvidos em cada episódio ou depoimento registrado.

Esses relatórios constituíram o material de análise. A perspectiva teórica adotada para a análise foi o construcionismo social (Gergen, 2010) tomando como pressuposto que os sentidos sobre a realidade são criados através de nossas atividades comunicacionais e colaborativas; de que nossas construções de sentidos sobre o mundo estão enraizadas em nossas relações sociais, em discursos elaborados em comunidades ou por diferentes tradições culturais que, por sua vez, referenciam de algum modo nossas crenças, ações e entendimentos sobre "qualquer coisa tradicionalmente aceita como verdadeira, racional ou correta" (Gergen, 2010, p.22). 'Nesse sentido, 'falar a verdade' é falar de uma forma que confirme a tradição de uma determinada comunidade" (Gergen, 2010, p. 25).

\section{Resultados e Discussão}

A Dificuldade de reconhecer as situações envolvendo Sigilo e Privacidade em meio ao fluxo de ações assistenciais e organizacionais

Desde os primeiros contatos dos auxiliares de pesquisa com a equipe do
SAE, seja na etapa de apresentação do estudo, passando pelos momentos das observações etnográficas, o tema da privacidade e do sigilo foi muito citado e valorizado pelos trabalhadores. "Manter $o$ sigilo" era descrita como uma das principais preocupações da equipe do SAE quando indagados sobre "o que acreditavam ser um bom atendimento, um atendimento humanizado no SAE". Segundo a coordenação era válido que o serviço atendesse a outras demandas de saúde, que não somente aquelas previstas para um SAE, pois assim não criava "aquela coisa de que se entrou ali, tem aids". Esse tipo de depoimento evidencia que em uma cidade pequena, onde as pessoas se conhecem intimamente ou "de vista", cujo serviço localiza-se no entorno de uma das principais praças da cidade, com grande circulação da população, há o risco de que ao ser visto entrando nesse serviço, as pessoas sejam identificadas, e desvalorizadas, como portadoras do vírus da aids.

No início do trabalho de campo, um dos profissionais ao se apresentar e cumprimentar os auxiliares de pesquisa na recepção do serviço reconheceu uma das acadêmicas e disse: "A Rita já conheço, já esteve aqui fazendo o exame com agente" (teste anti-HIV). Em seguida questionou: “Já veio buscar o resultado? Procurei seu exame e não o encontrei". Segundo anotações em diários de campo, alguns 
pesquisadores se olharam, esboçaram um leve sorriso, sem emitir algum comentário; nenhum trabalhador se manifestou, enquanto Rita, gaguejando, disse: "Ah ta... eu vim buscar".

Em se tratando de um estudo etnográfico em que pesquisadores se introduzem numa realidade a ser compreendida, buscou-se na análise valorizar as dimensões relacional e intersubjetiva. Com base na perspectiva construcionista social, a realidade é constituída por nossas percepções e descrições sobre as coisas, compartilhadas em nossos diálogos e performances, referenciadas por diferentes discursos, comunidades e tradições (Gergen, 2010).

$\mathrm{Na}$ tradição dos discursos sobre a ética no trabalho em saúde ou da "comunidade técnica ou acadêmica das profissões de saúde", a atitude do profissional descrita acima é entendida como desrespeito ao direito dos usuários no caso, o direito da auxiliar de pesquisa (também usuária do SUS) - ao sigilo sobre quaisquer exames e consultas que realizem em um serviço. Além disso, há uma impressão de "desorganização" do serviço que afetaria os usuários, pela pouca aceitação ou expectativa social de que um serviço "perca" ou "não encontre" o exame de um paciente.

Outro episódio ligado ao tema ocorreu na ocasião de uma das primeiras reuniões entre a equipe do serviço e a equipe da universidade, com a finalidade de que todos se conhecessem e de se detalhar a proposta de pesquisa, ocasião em que a equipe do SAE fez, novamente, menções sobre o quanto a "questão do sigilo é importante nesse tipo de serviço”. Num determinado momento em que uma das auxiliares de pesquisa se identificou como moradora nascida no município, foi lhe perguntado por um dos trabalhadores quem eram seus pais. Assim que a pesquisadora respondeu, um dos profissionais afirmou conhecê-los e complementou: “ $A h$ ! $O$ Evaldo (nome do pai da pesquisadora) sei... Esteve aqui semana passada, pegando camisinha com a gente".

A situação, se analisada sobre a ótica avaliativa, da manutenção ou não do sigilo profissional, evidencia que a privacidade de um indivíduo, ausente no momento do diálogo, foi indevidamente exposta a terceiros, incluindo uma pessoa com ligações de parentesco, sua filha. Algumas indagações emergem e nos dão "pistas" sobre as possíveis repercussões de situações como essa para os envolvidos. Explicitamse, nesse episódio, temas ligados às esferas morais, como a sexualidade ou o matrimônio, cuja produção de estigmas e subseqüentes discriminações tendem a ocorrer em relação àqueles que se "desviam" dos padrões mais aceitos como "corretos". No contexto de uma cidade 
pequena e interiorana, as referências de filiação e de parentesco são muito valorizadas nas relações sociais; inclusive, alguns atributos dos progenitores por vezes são atribuídos, imaginariamente, à sua prole, ou ainda, a conduta dos primeiros serve de critérios para julgamentos não somente dos próprios, como, também, de seus familiares. Seria Evaldo um homem casado, solteiro ou divorciado? $\mathrm{Na}$ moralidade local, o que pode representar um homem "bem casado", "pai de família", buscar preservativo? Que tipo de opinião sua filha teria a respeito? No discurso da saúde pública, Evaldo seria um sujeito "consciente, informado, que se previne". E na ótica da cultura local? Possivelmente, se casado, poderia ter questionada sua fidelidade conjugal ou de sua esposa. $\mathrm{Na}$ "fofoca" cotidiana as curiosidades poderiam ser: "foi só buscar preservativo ou faz algum tipo de tratamento? Qual tratamento? Para a aids? Usa preservativo com quem? Com a esposa ou "pula a cerca"?

Nas supervisões ocorridas durante a realização do trabalho de campo, a equipe de auxiliares de pesquisa e a coordenadora do estudo discutiram os dois episódios acima descritos. Inquietava-nos a semelhança das situações quanto ao fato das “exposições" se configurarem nos momentos de interação entre integrantes da equipe de pesquisa e os do serviço. Estávamos "surpresos”, pois elaborávamos, enquanto grupo, um determinado questionamento: se tais "deslizes", como chamávamos, estão ocorrendo assim em relação "a nós”, que "já" explicitamos estar pesquisando sobre "como o serviço acolhe as pessoas", "se é humanizado", seriam, então, esses episódios muito frequentes ou "mais graves" em relação aos usuários em geral, no cotidiano assistencial?

Várias interpretações foram coproduzidas durante as conversações do grupo de pesquisa a fim de compreender esses episódios não somente numa perspectiva avaliativa, que "julga" alguns quesitos da qualidade assistencial e da humanização, mas também, quanto aos seus sentidos contextuais (momento da interação), locais (cultura da cidade) e quanto aos seus significados socioculturais (imaginário e práticas sociais mais abrangentes que extrapolam a realidade local). Nesta análise, obviamente reconhecemos a parcialidade de nossas "verdades", dado que somos sujeitos imersos em determinadas tradições ou comunidades como "a científica", "a da saúde", "a da psicologia", "a dos defensores da humanização", etc.

Do ponto de vista das normativas ético-profissionais produzidas no interior das comunidades acima mencionadas, compreende-se o primeiro episódio como uma situação em que houve desrespeito à privacidade da pessoa em questão, ao não se 
manter a conduta do sigilo profissional. O entendimento e a intenção do trabalhador, por sua vez, pareciam ser outros - ao falar na presença dos "colegas de faculdade" de Rita, ali como pesquisadora, que ela tinha feito "o exame”, que por sua vez não estava sendo encontrado - ele tinha a intenção de aproximação. O comentário sobre um assunto que interessava à interlocutora tinha o sentido de expressar que ela não era uma "total desconhecida" para o profissional ou para a instituição. Durante a reunião da equipe de pesquisa conversou-se que embora $o$ trabalhador não falasse explicitamente em teste anti-HIV, Rita sabia que seu exame era esse. Segundo os colegas pesquisadores presentes no episódio, quando o profissional usou a expressão " $O$ exame”, num local socialmente reconhecido por realizar teste anti-HIV, o entendimento elaborado sobre a situação foi que se tratava do mesmo.

Rita, por sua vez, mencionou na reunião que no momento do ocorrido sentiuse constrangida quando o profissional de saúde a expôs na frente dos colegas de pesquisa e de outros profissionais; e que pouco importava se o exame estava ou não "desaparecido"; e que se sentiu "desconcertada".

Analisou-se, também, que no episódio em questão Rita não estava em uma relação propriamente de "usuárioprofissional da saúde", uma vez que ela não tinha ido ao serviço em busca do resultado de seu teste. Sendo a interação de outra natureza, que implicação ela teve no desenvolvimento do então episódio de "quebra de sigilo"? Como a interação ocorreu no momento em que a equipe da universidade estava se aproximando do serviço, trabalhou-se com a idéia de que nessas circunstâncias não cabia a identidade de Rita como usuária do SUS. Logo, a prerrogativa de ter sua privacidade preservada, no que referia à realização de seu teste anti-HIV foi "flexibilizada"; sua identidade como pesquisadora produziu a confusão de papéis, o que contribuiu para esse "deslize ético" (descumprimento da conduta do sigilo profissional).

Outro sentido emergente em ambos os episódios, é que segundo as concepções dos trabalhadores em questão, aquilo que entendiam e nomeavam como "manter $o$ sigilo" se restringia, ou era mais fortemente associado, à conduta individual de manter em sigilo as informações sobre "quem eram as pessoas da cidade que faziam tratamento por aids". Em nenhum momento esse tipo de informação foi revelado aos pesquisadores que, por sua vez, não fizeram indagações a respeito.

Outro aspecto considerado foi o fato de nós pesquisadores estarmos ali, "introduzidos no campo", o que pode ter contribuído para a produção intersubjetiva de relações de proximidade e de 
identificação entre pesquisadores e trabalhadores que flexibilizassem as regras de conduta inerentes ao sigilo profissional, favorecendo que os assuntos fossem compartilhados sem esse "filtro". Os pesquisadores, na medida em que conversavam e observavam, passavam a ser percebidos pela equipe do SAE como "nós", "da nossa área”, e não como "os outros", como usuários do serviço. Rita, naquele episódio, não era representada como a Rita usuária, e sim como a Rita pesquisadora e estudante de psicologia.

Outros episódios foram observados em que o sigilo emergiu como questão, não somente envolvendo as aproximações entre a equipe de pesquisa e a equipe do serviço, mas sim no que concerne à assistência de modo geral, nas relações com os usuários. Um desses episódios envolveu dois profissionais de saúde e ocorreu na sala de espera, quando ambos conversavam sobre uma família cujos integrantes haviam feito exames sorológicos no SAE. Embora não tenham mencionado quais exames, se referiram à família como "aquela que alguém já teve hepatite”. Os trabalhadores explicitavam os nomes do casal e de seus filhos, seu endereço residencial e local de trabalho. Isto se deu no momento em que alguém telefonou ao serviço perguntando se os exames da família haviam chegado e, ao se comunicarem entre si (um ao telefone e o outro procurando pelos exames no arquivo), os profissionais falavam em voz alta essas informações, mesmo na presença de usuários que aguardavam atendimento no mesmo espaço.

Outra situação observada evidencia o modo positivo (do ponto de vista das diretrizes) com que uma profissional da equipe manteve a conduta do sigilo em um tipo de situação muito corriqueira nos serviços: aquela em que terceiros vão buscar o resultado de exames e sorologias a pedido de alguém. Uma pessoa chegou ao SAE dizendo que havia ido buscar o exame da amiga, um profissional do serviço afirmou que o exame não poderia lhe ser entregue. $\mathrm{O}$ desfecho se deu quando a mulher que tentava pegar o exame ligou para a usuária em questão, que autorizou ao telefone que o exame fosse entregue. Foi possível constatar que o profissional conhecia ambas as pessoas envolvidas.

O fluxo de ações organizacionais para retorno aos pacientes de seus resultados do teste anti-HIV e das sorologias se mostrou de especial relevância para o tema pesquisado. $\mathrm{O}$ processo de trabalho seguia uma determinada rotina que constrangia as pessoas algumas vezes, criando uma situação de iminente quebra de sigilo e exposição da privacidade. A equipe nos explicava: "quem deu negativo, [nos termos dos profissionais], obtém o retorno de seu exame na recepção; quem deu positivo, [para alguma DST ou para o HIV], 
seu exame não vai para o arquivo da recepção". Ao procurar pelo seu resultado de exames, as pessoas com diagnósticos confirmados recebiam instruções do tipo: "tem que aguardar um pouquinho pra passar com o médico"; "vamos agendar uma consulta para você", "o coordenador vai falar com você", ou até mesmo nenhuma instrução específica. Daí os usuários tinham que lidar com o silêncio, com a incerteza se o resultado do exame retornara ou não da capital, ou com as expressões faciais que transmitiam a idéia de gravidade ou de pesar, em especial quando se tratava de confirmação de soropositividade. Ao retornarem ao SAE, os envelopes dos exames, fechados, eram abertos e analisados somente pelo coordenador do serviço, que fazia uma triagem: os positivos para HIV ficavam com ele e os negativos iam para o arquivo. A devolutiva ao usuário em caso de exames alterados era feita somente pelo médico solicitante ou pelo coordenador, com formação em psicologia.

Esse tipo de fluxo se constituía, mesmo que de forma indireta, em quebra de sigilo e exposição dos usuários, além de desencadear ansiedades, medos e tensões do ponto de vista de quem não tinha seu exame encontrado no arquivo no momento em que fosse buscá-lo no serviço. Uma situação observada envolvendo duas usuárias na sala de espera constitui-se um exemplo de exposição. Uma delas teve seu exame procurado e não encontrado no arquivo, após um tempo de espera ela ingressou em uma sala e foi atendida pelo coordenador, quando então ao término desse procedimento ela saiu do consultório com semblante de choro. A outra usuária, que permanecia ainda sentada aguardando, estabeleceu contato visual com um dos auxiliares de pesquisa e, por sua expressão facial e comentário, percebeu-se uma postura de empatia. Ela disse: "Nossa! Coitada. Deve ter dado alguma coisa no exame dela".

Outros procedimentos e fluxos de ações no serviço, observados ou relatados, são emblemáticos para a presente discussão e ampliam seu alcance. Especificamente com relação à proteção das pessoas com HIV do estigma e da discriminação, observou-se a falta de cuidado sistemático na realização de buscas ativas de usuários, ou seja, sem seu consentimento prévio. Outra prática usual do serviço, de extrema importância com relação ao tema, refere-se à organização do atendimento para pacientes com aids consultarem com médicos especialistas ou realizarem exames complexos. Como ambos os procedimentos ocorriam na capital do Estado, havia um dia fixo da semana para essas viagens, reunindo um grupo de usuários, utilizando-se de veículo com identificação do $\mathrm{SAE}$ e do Programa Municipal de DST/Aids. Uma 
pessoa que vive com HIV relatou na sala de espera a um dos pesquisadores: "o carro passa, daí já viu, os vizinhos já vêem”, evidenciando as repercussões ao se tornar possível a identificação ou a confabulação por vizinhos e familiares, acerca das pessoas que vivem com HIV, construindo-se um clima de "suspeita" em torno da vida privada.

\section{"Usuária nervosa": sua privacidade em risco por uma suposta quebra de sigilo}

Alguns trabalhadores relataram aos observadores uma situação ocorrida durante o período em que os pesquisadores realizavam as observações, em um dia que eles não estavam no serviço. Referiam-se a uma usuária nervosa que havia procurado o SAE acusando um dos integrantes da equipe de fazer comentários pejorativos sobre ela e sobre o fato dela ser soropositiva a algumas pessoas que conheciam em comum. Alguns trabalhadores destacaram que a usuária em questão, de fato acompanhada pelo SAE, estava emocionalmente abalada, muito nervosa e agressiva, pois alegava que seu relacionamento afetivo com parceiro fixo estava em risco, o qual supostamente não tinha conhecimento de sua soropositividade até os comentários a respeito, a partir da suposta quebra de sigilo por parte de uma pessoa da equipe do SAE.
Pouco tempo depois, o profissional citado como aquele que havia feito tais comentários sobre a usuária, deixou o serviço após solicitar transferência para outro local. Segundo depoimentos de alguns trabalhadores, a mesma usuária também o acusava de ter tirado fotos com uso do celular em momentos em que ela esteve no SAE e que estaria mostrando essas fotos a outras pessoas. A veracidade do fato, por sua vez, não cabe ao estudo avaliar, mas sim, de considerá-lo da perspectiva das práticas, interações, sentidos e significados suscitados na comunicação entre os profissionais. A maior parte dos trabalhadores acreditava que esse colega de trabalho realmente havia tido uma conduta inadequada do ponto de vista ético, pois destacavam que em outros momentos alguns deles já haviam presenciado o mesmo trabalhador incidindo em práticas semelhantes, ou seja, nos termos dos trabalhadores, "fazendo comentários sobre outros usuários do serviço". O que circulou nas conversações na instituição foi que "com medo da usuária nervosa" que o ameaçava, o trabalhador solicitou sua transferência.

\section{Considerações Finais}

Se inicialmente os pesquisadores tinham a expectativa de que o material de análise seria, predominantemente, relativo à 
assistência das pessoas com HIV envolvendo eventuais exposições indevidas ou, ao contrário, as estratégias para proteção de sua privacidade, os dados encontrados extrapolaram tal expectativa. Os resultados evidenciaram situações de negligência quanto ao direito à privacidade das pessoas em geral em um SAE, com "quebra de sigilo" ou iminência desta, em variadas circunstâncias relacionadas ao processo de trabalho, e não somente em relação às pessoas que faziam tratamento por aids. Isso se relaciona com o fato de que o serviço realizava diferentes exames diagnósticos e se constituía como local de acesso ao preservativo para a população em geral, o que expande os horizontes e as implicações dos resultados.

O material das observações, como se pôde constatar, aponta para a maior amplitude das questões envolvendo sigilo e privacidade nesse tipo de serviço e a necessidade de compreender os sentidos das práticas sociais em torno desses temas, as pessoas envolvidas e a realidade local. Em uma cidade pequena e interiorana, o fato das pessoas se conhecerem, saberem e valorizarem as referências à filiação e parentesco, "quem é o pai de tal pessoa", aponta para a tênue fronteira entre a vida social e a ordem privada. Essa realidade suscita a discussão sobre as implicações da exposição "corriqueira" da privacidade, no que concerne aos assuntos ligados à saúde, à vida sexual e conjugal das pessoas em geral e, especialmente, das pessoas que vivem com HIV pelo rico de serem alvo de discriminações.

A realidade de uma cidade onde boa parte das pessoas tem conhecimento sobre a vida das outras, pode favorecer negligências ao sigilo e exposição da privacidade que, se avaliadas do ponto de vista das diretrizes e normas técnicas, são inadequadas. A preocupação com a não exposição indevida das pessoas atendidas, por parte da equipe estudada, embora estivesse no plano discursivo, mostrou-se frágil e com falhas no plano operacional, ou seja, no acolhimento às pessoas e durante procedimentos organizacionais. Entretanto, da perspectiva dos trabalhadores tais situações não eram, geralmente, percebidas desse modo, tampouco eles pareciam conscientes de estarem, em determinados momentos, incorrendo em falhas técnicas e éticas; portanto, não havia intencionalidade, mas sim falhas associadas ao caráter trivial ou habitual conferido às condutas cotidianas.

As negligências ao sigilo na atenção em saúde sejam por meio do que é verbalmente explicitado, ou por meio de ações indiretas (fluxo, procedimentos, e intervenções) como os resultados mostraram, expõem os usuários em sua privacidade e intimidade, ferem a confidencialidade e impactam 
negativamente o acolhimento e a humanização do atendimento. Isso se evidencia especialmente em serviços, como o estudado, que lidam com uma doença estigmatizada como a Aids e com a saúde sexual, envoltas por valores morais compartilhados e condicionadas à normatividade social.

Isso se mostrou evidente no caso da "usuária nervosa", uma mulher que vive com HIV, que em função de uma provável quebra do sigilo profissional por parte de um dos trabalhadores, experimentou sofrimento e repercussões em seu relacionamento com o parceiro. Segundo Bessa (1997, p. 104 citado por Brasil, 2008)

a aids é percebida e vivenciada como uma doença do outro, daquele que é visto como estranho, diferente, marginal à sua própria sociedade. (...) Ser diagnosticado doente de AIDS é um passaporte para o outro lado, numa sociedade dividida entre "nós" e "eles". Mesmo reconhecendo que essa divisão é frágil, e fluida, ela existe e marca os espaços de cada um a partir dela (p. 30).

Portanto, revelar a soropositividade de uma pessoa sem seu consentimento constitui uma violação de seu direito à privacidade e ao sigilo profissional nos serviços de saúde. (Neves, 2003 citado por Abdalla e Nichiata, 2008).

Segundo Deslandes e Mitre (2009) a garantia do sigilo integra o cuidado integral e o acolhimento, pois o bem estar psíquico do paciente e a construção da confiança em relação ao tratamento e aos profissionais do serviço se firmam por meio do acordo tácito de respeito à privacidade e à intimidade.

Como evidenciaram os resultados, embora a equipe valorizasse o respeito ao sigilo no que tange a não revelar os resultados dos testes para HIV ou a identidade das pessoas em TARV (Terapia Antirretroviral), desrespeitavam-no durante alguns processos de trabalho envolvendo, inclusive, questões assistenciais não somente das pessoas que vivem com HIV. A noção de confidencialidade associava-se, mais restritamente, à postura profissional de médicos ou enfermeiros que deveriam manter em sigilo assuntos abordados no consultório, entre "quatro paredes". Pelas situações observadas ficou evidente que não é somente no ato de se expressar verbalmente a terceiros, por parte de um trabalhador de saúde sobre assuntos da privacidade dos pacientes, que pode ocorrer negligência ao sigilo. Determinados procedimentos e processos ligados à organização do serviço, além da conduta verbal dos profissionais, também podem violar o direito ao sigilo e expor, mesmo que indiretamente, a privacidade das pessoas.

No caso do presente estudo esses procedimentos envolviam o fluxo de retorno de exames, a explicitação do diagnóstico 
aos pacientes, a organização de arquivos, as discussões de casos por telefone entre os serviços, a organização dos atendimentos em especialidade e exames complexos, cujas idas à capital com automóvel identificado culminavam em algum tipo de associação entre as pessoas que o utilizavam e a aids. Como ensina Ayres (2001) os momentos assistenciais envolvendo profissionais e usuários se dão num cenário de encontros intersubjetivos, onde "a atitude 'cuidadora' precisa se expandir mesmo para a totalidade das reflexões e intervenções no campo da saúde" (p.71).

Segundo nossas análises, a equipe operava, de modo geral, com uma noção parcial ou reduzida de sigilo. Havia um baixo reconhecimento de que a organização do trabalho (fluxo de ações, procedimentos e condutas) poderia violar o sigilo profissional, tanto quanto aquilo que fosse transmitido verbalmente a terceiros, descumprindo o acordo explícito ou implícito de restringir ao conhecimento de ambos (profissional e pessoa atendida), determinado assunto ou procedimento realizado, seja vir ao serviço para buscar preservativo ou para fazer o teste anti-HIV.

Os SAE(s) de todo Brasil são serviços que, além do acompanhamento de saúde das pessoas que vivem com HIV/Aids, devem realizar ações de prevenção das DST(s), consultas clínicas, sorologias, exames sorológicos, teste anti-
HIV, aconselhamentos pré e pós teste, ações educativas, disponibilização de preservativos, orientações, entre outras (Oliveira, Landroni, Silva \& Ayres, 2005). Nesse sentido, é necessário o reconhecimento institucional da dimensão do sigilo e da privacidade, assim como de sua relação com os estigmas $\mathrm{e}$ as discriminações em relação à aids, ao gênero ou à etnia, em função de práticas ou orientações sexuais, ou ainda, em função de comportamentos que não são "bem vistos", segundo a cultura local.

No caso de municípios pequenos e interioranos em que o anonimato é praticamente impossível, diferentemente dos grandes centros urbanos, assim como são mais tênues os limites entre a privacidade e o convívio social, é necessário que as equipes de saúde possam conversar e reconhecer suas especificidades locais, tornando-se mais sensibilizadas e preparadas para manejar recursos e pactuar práticas que protejam o direito à privacidade, mitiguem estigmas e discriminações, se tornado mais humanizados. $\mathrm{O}$ respeito à privacidade como um direito do usuário, sua relação com a humanização do atendimento e com a proteção frente ao estigma são temas éticos a serem mais fortemente incorporados na reflexão cotidiana das equipes dos SAE (s), em seus momentos de capacitação, planejamento e avaliação. 
A problematização do tema junto às equipes de SAE(s) em localidades como a que se desenvolveu o estudo é relevante para que novas práticas possam ser implementadas. A elucidação dos sentidos das práticas e das situações envolvendo sigilo e privacidade deve levar em consideração as tradições locais, balizada pelas referências técnicas e éticoprofissionais, entre essas as da $\mathrm{PNH}$ e do Programa Nacional de DST/Aids. Seria necessário questionar $\quad$ o caráter supostamente "natural" das práticas e das crenças, refletindo sobre suas implicações para a vida pessoal e social das pessoas em questão.

A superação das dificuldades de interação entre profissionais e usuários de serviços de saúde, reclamadas pelas propostas de humanização, não são um desafio exclusivamente técnico (Oliveira, Landroni, Silva \& Ayres, 2005). Deslandes (2004) aponta a natureza social desse desafio, destacando a importância de aspectos tais como a cultura organizacional e recursos para sua mudança, as relações assimétricas entre profissional-usuário e a hegemonia de uma objetividade científica utilitarista.

É preciso reconhecer que a organização do processo de trabalho em serviços como os SAE (s), tanto está sujeita às vicissitudes dos significados sociais das doenças, dos diagnósticos e dos hábitos da cultura local (que podem, por exemplo, "flexibilizar" contratos como o do sigilo), como, simultaneamente, repercute nas experiências cotidianas das pessoas assistidas, dado que a assistência em saúde produz-se como realidade objetiva e simbólica. Como viver suas relações afetivas e sociais, sendo identificadas por essa ou aquela doença? Por esse ou aquele comportamento? Esse ou aquele tratamento?

Abdalla e Nichiata (2008) afirmam que a complexidade e a variedade dos problemas suscitados pela Aids exigem respostas por parte dos serviços de saúde que considerem não somente os aspectos clínicos, mas também os impactos sociais, psicológicos e econômicos associados aos estigmas e preconceitos que ainda a permeiam, constituindo desafios aos serviços de aids e de doenças sexualmente transmissíveis.

As contribuições da noção de atenção psicossocial, proposta no campo da sexualidade e da assistência em DST/Aids por Paiva (2007), podem ajudar na superação desses desafios. Implementar a atenção psicossocial implica o reconhecimento por parte dos trabalhadores da saúde de que toda experiência de adoecimento, assim como de produção pessoal da própria saúde, possui uma dimensão psicossocial integrada a essa experiência (que se refere às repercussões 
psicológicas e sociais na vida das pessoas). Isso tem especial relevância ao se planejar e desenvolver a assistência em saúde.

As propostas de Ayres (2009) sobre o Cuidado em saúde também são bem vindas, pois parece profícuo pensar

\begin{abstract}
(...) o cuidado como um constructo filosófico, uma categoria com a qual se quer designar simultaneamente, uma compreensão filosófica e uma atitude prática frente ao sentido que as ações de saúde adquirem nas diversas situações em que se reclama uma ação terapêutica, isto é, uma interação entre dois ou mais sujeitos visando o alívio de um sofrimento ou o alcance de um bem-estar, sempre mediada por saberes especificamente voltados para essa finalidade (Ayres, 2004a, p.74).
\end{abstract}

Assim, se pensarmos a ação terapêutica de informar a um paciente o resultado de seu teste anti-HIV, nas perspectivas do Cuidado e da atenção psicossocial, teríamos que nos atentar aos vários sentidos e modos de se fazer isso, incluindo a reflexão crítica sobre a dimensão relacional intersubjetiva "trabalhador-usuário-serviço-cidade" e, também, sobre os fluxos de procedimentos envolvendo essa ação terapêutica (em que dias, em que espaços, em que horários, os diálogos entre quais pessoas, os exames estando aos cuidados de quem, aonde, etc.). Isso porque, dessas circunstâncias planejadas cuidadosamente, ou não, decorrem implicações tais como: o respeito ou não à privacidade, a negligência ou a garantia do sigilo, as quais podem ser indutoras ou limitadoras do bem-estar, de sofrimento, qualidade de vida e de cidadania para os envolvidos.

Desse modo, no cenário amplo do trabalho em saúde, o sigilo deve nortear as ações de gestores e profissionais a fim de humanizar a atenção não somente às pessoas que vivem com HIV, protegendo-as das discriminações, mas também a todo e qualquer cidadão, adulto ou criança, homem ou mulher, em seus assuntos, necessidades, problemas e dúvidas relacionadas ao exercício da sexualidade e à saúde sexual, cujos direitos nessas esferas se constituem como direitos humanos. Portanto, os sentidos de humanização extrapolam idéias como "atender bem", "com delicadeza" e "com educação"; o cuidado humanizado envolve centralmente a noção de respeito aos direitos das pessoas, em especial o direito à preservação de sua privacidade e intimidade em toda e qualquer circunstância assistencial.

O presente trabalho teve por objetivo, portanto, contribuir com a tese de que a manutenção do sigilo e a construção da confidencialidade - enquanto dimensões centrais da proposta de humanização da assistência à saúde devem ser compreendidas e operadas numa perspectiva, além de ampliada, 
interdisciplinar e institucional. Ou seja, para além da idéia do compromisso de sigilo entre um médico (ou um profissional que presta atendimento individual) e seu paciente, na situação de intimidade do consultório. O sigilo, como conduta de respeito à privacidade e intimidade, deve oferecer parâmetros para todos os momentos assistenciais e processos que constituem o trabalho em saúde.

Conclui-se, portanto, que a humanização e a integralidade da assistência - especialmente em DST/Aids ou em saúde sexual - podem se consolidar, na medida em que o trabalho prático se sustente por noções como a de atenção psicossocial, do Cuidado, e do acolhimento com respeito à privacidade e à intimidade das pessoas atendidas. É necessário, no entanto, um processo institucional contínuo de "auto-análise" diante de possíveis ou aparentes "tensões", "contradições", entre esses referenciais e os valores, crenças e as práticas legitimadas pela cultura institucional e pelos padrões de sociabilidade loco-regionais.

\section{Notas}

${ }^{1}$ Refere-se à pesquisa, desenvolvida em 2009 e 2010: Acolhimento e Acesso: consolidando a integralidade e o direito à saúde. Um estudo junto à rede de saúde de um município de pequeno porte no Estado de Mato Grosso do Sul - MS, no escopo do qual ocorreram observações etnográficas, cujo material é objeto de discussão do presente trabalho. O projeto foi aprovado pela Comissão Nacional de Ética em Pesquisa (CONEP), número de protocolo 1720, e as observações foram permitidas (via assinatura de termo de autorização) pela Secretaria Municipal de Saúde e pela coordenação do SAE, com ciência da equipe sobre o projeto de pesquisa em desenvolvimento.

${ }^{2}$ Os cargos são genericamente referidos no masculino ao longo de todo o texto para não facilitar qualquer identificação dos informantes ou do serviço, preservando o anonimato. Pela mesma justificativa não é divulgado o município onde se desenvolveu o estudo e os nomes citados em Resultados e Discussão são fictícios, respeitando os princípios éticos assumidos junto aos participantes e ao órgão municipal.

\section{Referências}

Ayres, J. R. C. M. (2001). Sujeito, intersubjetividade e práticas de saúde. Ciênc. saúde coletiva [online].6(1), 63-72.

Ayres, J. R. C. M. (2004a.). Cuidado e reconstrução das práticas de saúde. Interface: Comunicação, Saúde, Educação. 8(14), 73-91. 
Ayres, J. R. C. M. (2004b.). O cuidado, os modos de ser (do) humano e as práticas de saúde. Saúde e Sociedade. 13(3), 16-29.

Abdalla, F. T. M., \& Nichiata, L. Y. I. (2008). A Abertura da privacidade e o sigilo das informações sobre o HIV/Aids das mulheres atendidas pelo Programa Saúde da Família no município de São Paulo, Brasil. Saude soc. [online], 17(2), 140-152.

Brasil. (2005). Ministério da Saúde. Programa Nacional de DST/HIV e Aids. Intensificando a prevenção ao HIV - UNAIDS Documento Referencial Políticas de Prevenção ao HIV/Aids. Consultado em 2 de Julho de 2009 através http://www.aids.gov.br/data/document s/storedDocuments/\%7BB8EF5DAF23AE-891-AD36-

1903553A3174\%7D/\%7BDC3056528750-442F-BD71-

\section{B1864CECAEFE\%7D/intensificando}

_a_prevencao_hiv.pdf

Brasil. (1999). Ministério da saúde. Coordenação Nacional de DST e AIDS. Política Nacional de DST/aids: princípios e diretrizes. (1.ed). Brasília: Ministério da Saúde, 1-90.

Brasil. (2006). Ministério da Saúde. Secretaria de Atenção à Saúde. Núcleo Técnico da Política Nacional de Humanização. Acolhimento nas práticas de produção de saúde (2.ed.). Brasília: Ministério da Saúde.

Brasil. (2006a). Ministério da Saúde. Secretaria de Atenção à Saúde. Departamento de Ações Programáticas Estratégicas. Direitos sexuais, direitos reprodutivos e métodos anticoncepcionais. Brasília: Ministério da Saúde. (Série F. Comunicação e Educação em Saúde), (Série Direitos Sexuais e Direitos Reprodutivos; caderno n.2), 1-52.

Brasil. (2008). Ministério da Saúde. Secretaria de Vigilância em Saúde. Programa Nacional de DST e Aids. Direitos Humanos e HIV/Aids: avanços e perspectivas para o enfrentamento da epidemia no Brasil. Brasília: Ministério da Saúde. (Série B. Textos Básicos de Saúde), (Série Parcerias e Mobilização Social; n. 6), 1-168. ISBN 978-85-334-1522-5.

Brasil. (2010). Ministério da Saúde. Secretaria de Atenção à Saúde. Política Nacional de Humanização. (Série B. Textos Básicos de Saúde), (Cadernos HumanizaSUS ; v. 1), 1242 Consultado em 07 de Março de 2012 através http://bvsms.saude.gov.br/bvs/public acoes/cadernos_humanizaSUS.pdf Carrara, S., \& Simões, J. A. (2007). Sexualidade, cultura e política: a trajetória da identidade homossexual 
masculina na antropologia brasileira. cadernos pagu (28) janeiro-junho, 6599.

Castanheira, E. R. L. (2002). Avaliação da assistência ambulatorial a pessoas vivendo com HIV/Aids em serviços públicos no estado de São Paulo: relações entre qualidade $e$ organização do processo de trabalho. Tese de Doutorado apresentado a Faculdade de Medicina Preventiva da Universidade de São Paulo, São Paulo.

Corrêa, S., \& Ávila, M. B. (2003). Direitos sexuais e reprodutivos. Pauta global e percursos Brasileiros. In: Berquó, E. (Org.). Sexo e Vida: Panorama da Saúde Reprodutiva no Brasil. (pp. 1778). Campinas: UNICAMP.

Deslandes, S. F. (2004). Análise do discurso oficial sobre a humanização da assistência hospitalar. Ciênc. saúde coletiva [online]. 9(1), 7-14.

Deslandes, S. F., \& Mitre, R. M. (2009). A. Processo comunicativo e humanização em saúde. Interface (Botucatu) [online]. 13, suppl.1, 641-649.

GERGEN, K. J. Construcionismo social: um convite ao diálogo. Rio de Janeiro: Instituto Noos, 2010.

Goffman, E. (1963). Estigma: Notas sobre a Manipulação da Identidade Deteriorada. $4^{\mathrm{a}}$ ed. Rio de Janeiro: Ed. Guanabara.
Gracia, D. (1998). La confidencialidad de los datos geneticos. In: Gracia D. Etica y vida: etica de los confines de la vida. (pp.137-50). Santa Fe de Bogota: Buho.

Galvão, M. T. G., Cerqueira, A. T. B. R., \& Marcondes-Machado, J. (2004). Avaliação da qualidade de vida de mulheres com HIV/AIDS através do HAT-QoL. Cad. Saúde Pública [online]. 20(2), 430-437.

Garrido, P. B., Paiva, V., Nascimento, V. L. V., Sousa, J. B., \& Santos, N. J. S. (2007.). Aids, estigma e desemprego: implicações para os serviços de saúde. Rev. Saúde Pública. 41(2) 72-79.

Hera. Health, Empowerment, Rights \& Accoutability. (1999). Direitos sexuais e reprodutivos e saúde das mulheres: idéias para ação. Consultado em 5 de Maio de 2011 através http://www.iwhc.org/hera

Matumoto, S., Mishima, S. M., Fortuna, C. M., \& Pereira, M. J. B. (2002). A comunicação como ferramenta para o acolhimento em unidades de saúde. In: Simpósio Brasileiro de Comunicação em Enfermagem. Anais eletrônicos Escola de Enfermagem de Riberão Preto - USP. Consultado em 13 de Maio de 2011 através http://www.proceedings.scielo.br/sciel o.php?script=sci_arttext\&pid=MSC00 
$\underline{00000052002000100050 \& \operatorname{lng}=\mathrm{pt} \& \mathrm{nr}}$

$\underline{m=a b n}$

Massarollo, M. K. B., Sacardo, D. P., \& Zoboli, E. L. C. P. (2006). Autonomia, privacidade e confidencialidade. In: Oguisso, T., Zoboli, E. L. C. P. (Org.). Ética e bioética: desafios para a enfermagem e a saúde. (pp. 136-152). São Paulo: Manolle.

Oliveira, L. A., Landroni, M. A. S., Silva, N. E. K., \& Ayres, J. R. C. M. (2005). Humanização e cuidado: a experiência da equipe de um serviço de DST/Aids no município de São Paulo. Ciênc. saúde coletiva [online]. 10(3) 689698.

Oliveira, A., Neto, J. C. S., Machado, M. L. T., Souza, M. B. B., Feliciano, A. B., \& Ogata, M. N. (2008). A comunicação no contexto do acolhimento em uma unidade de saúde da família de São Carlos, SP. Interface (Botucatu) [online]. 12(27) 749-762.

Parker, R., \& Aggleton, P. (2001). Estigma discriminação e Aids. pp. 45. Rio de Janeiro: ABIA -Associação Brasileira Interdisciplinar de Aids. (Coleção ABIA - Cidadania e Direitos, $\mathrm{n}^{\circ} 1$ ). Consultado em 5 de Outubro de 2009 através

http://www.abiaids.org.br/_img/media /colecao\%20cidadania\%20direito.pdf
Paiva, V., Lima T., Santos N., VenturaFilipe E., \& Segurado A. (2002). Sem Direito de Amar?: A Vontade de Ter Filhos Entre Homens (e Mulheres) Vivendo Com o HIV. Psicol. USP [online]. 13(2), 105-133.

Paiva, V. (2007, Outubro). Prevenção positHIVa: abordagem psicossocial, emancipação e vulnerabilidade. 1-27. Texto apresentado no seminário "Prevenção Posithiva: estado da arte". ABIA, Rio de Janeiro. Consultado em 22 de Setembro de 2009 através http://www.usp.br/nepaids/pdfs/preve ncao_positHIVa_VPaiva.pdf

Paiva, V. (2007). Sobre o direito ao amor: a sexualidade e a vontade de ter filhos entre Pessoas vivendo com HIV. Tese de Livre Docência apresentada ao Instituto de Psicologia, Universidade de São Paulo, São Paulo.

Silva, N. E. K., Oliveira, L. A., Figueiredo, W. S., Landroni, M. A. S., Waldman, C. C. S., \& Ayres, J. R. C. M. (2002). Limites do trabalho multiprofissional: estudo de caso dos centros de referência para DST/Aids. Rev. Saúde Pública [online]. 36(4) suppl. 108-116.

Silva, C. R. C. (2004). A politização da dor $e$ indignação: $o$ processo de fortalecimento dos modos singulares de participação de agentes comunitários de uma ONG/AIDS da 
grande São Paulo. Tese de Doutorado apresentado ao Instituto de Psicologia de São Paulo, São Paulo.

Souza, E. C. F., Vilar, R. L. A., Rocha, N. S. P. D., Uchoa, A. C., \& Rocha, P. M. (2008). Acesso e acolhimento na atenção básica: uma análise da percepção dos usuários e profissionais de saúde. Cad. Saúde Pública [online]. 24, suppl.1, pp. s100-s110.

Sales-Peres, S. H. C., Sales-Peres, A., Fantini, A. M., Freitas, F. D'. R., Oliveira, M. A., Silva, O. P., \& Chaguri, R. H. (2008). Sigilo profissional e valores éticos. Revista da Faculdade de Odontologia, Rio Grande do Sul, 13(1), 7-13. Consultado em 16 de Outubro de 2009 através http://www.upf.edu.br/seer/index.php /rfo/article/viewFile/583/377

Sá, M. C. (2009). A fraternidade em questão: um olhar psicossociológico sobre o cuidado e a "humanização" das práticas de saúde. Interface (Botucatu) [online]. 13, suppl.1, pp. 651-664.

\section{Renata Bellenzani: Docente da} Universidade Federal de Mato Grosso do Sul. Pesquisadora do Grupo de Pesquisa do CNPq/USP: NEPAIDS/USP (Núcleo de
Estudos para Prevenção da Aids). renatabellenzani@hotmail.com

Rúbia de Fátima Mendes: Acadêmica de Psicologia da Universidade Federal de Mato Grosso do Sul. rubiapsico@hotmail.com 